\title{
Feasibility of Crosslinked Acrylic Shape Memory Polymer for a Thrombectomy Device
}

\author{
Andrea D. Muschenborn, Keith Hearon, Brent L. Volk, \\ Jordan W. Conway, and Duncan J. Maitland \\ Biomedical Engineering Department, Texas A\&M University, 3120 TAMU, College Station, TX 77843, USA \\ Correspondence should be addressed to Duncan J. Maitland; djmaitland@tamu.edu
}

Received 29 August 2013; Revised 25 December 2013; Accepted 16 January 2014; Published 25 February 2014

Academic Editor: Hideki Hosoda

Copyright (c) 2014 Andrea D. Muschenborn et al. This is an open access article distributed under the Creative Commons Attribution License, which permits unrestricted use, distribution, and reproduction in any medium, provided the original work is properly cited.

\begin{abstract}
Purpose. To evaluate the feasibility of utilizing a system of SMP acrylates for a thrombectomy device by determining an optimal crosslink density that provides both adequate recovery stress for blood clot removal and sufficient strain capacity to enable catheter delivery. Methods. Four thermoset acrylic copolymers containing benzyl methacrylate (BzMA) and bisphenol A ethoxylate diacrylate (Mn 512, BPA) were designed with differing thermomechanical properties. Finite element analysis (FEA) was performed to ensure that the materials were able to undergo the strains imposed by crimping, and fabricated devices were subjected to forcemonitored crimping, constrained recovery, and bench-top thrombectomy. Results. Devices with 25 and 35 mole\% BPA exhibited the highest recovery stress and the highest brittle response as they broke upon constrained recovery. On the contrary, the $15 \mathrm{~mole} \% \mathrm{BPA}$ devices endured all testing and their recovery stress $(5 \mathrm{kPa})$ enabled successful bench-top thrombectomy in $2 / 3$ times, compared to 0/3 for the devices with the lowest BPA content. Conclusion. While the 15 mole $\%$ BPA devices provided the best trade-off between device integrity and performance, other SMP systems that offer recovery stresses above $5 \mathrm{kPa}$ without increasing brittleness to the point of causing device failure would be more suitable for this application.
\end{abstract}

\section{Introduction}

Thrombectomy devices are utilized endovascularly to remove blood clots and reestablish blood flow in an occluded artery. When the occluded artery is part of the neurovasculature, failure to reestablish blood flow in a timely manner results in a significant reduction in the oxygenation of brain tissue. Such an event is called acute ischemic stroke and occurs approximately every minute to someone in the US [1-3]. Of all ischemic stroke cases, $8-12 \%$ are fatal, and the 6month poststroke period for survivors renders this disease the leading cause of adult long-term disability $[1,2,4,5]$. To date, there is one drug, tissue plasminogen activator (tPA), and four devices, Merci Retriever (Stryker, California), Penumbra System (Penumbra Inc., California), Solitaire FR (ev3, California), and Trevo Retriever (Stryker, California), that have been approved by the US Food and Drug Administration (FDA) for the treatment of acute ischemic stroke [2, $3,6]$. However, the success rates of these clinical treatments remain significantly limited. Only $2-3 \%$ of ischemic stroke patients are eligible to receive tPA because of its narrow treatment time window and other exclusion criteria $[6,7]$. Consequently, tPA-ineligible patients are usually treated with one of the approved thrombectomy devices, which are often associated with other complications, including blood clot dislodgement and distal migration, limited device maneuverability, and arterial perforation [2, 8-10]. There remains a need to evaluate alternative materials and device designs that can enable rapid and successful reestablishment of blood flow in ischemic stroke patients.

The emergence of smart materials has given rise to the investigative development of numerous minimally invasive endovascular devices that exploit novel material capabilities. One such capability is shape memory, which is a material's ability to store temporary shape(s) and then actuate to a primary geometry when exposed to stimuli such as heat or moisture [11-13]. Shape memory alloys (SMAs), particularly nickel titanium (nitinol), have been used in the biomedical 
field for over 20 years [14]. Three out of the four FDAapproved devices for the treatment of ischemic stroke are made with nitinol. For example, the Merci Retriever is a nitinol wire that has been preshaped with a corkscrew geometry. The other two nitinol-based thrombectomy devices are self-expanding stents, Solitaire FR and Trevo. However, one major drawback of these devices is their length, which limits their placement and maneuverability during treatment [15].

Shape memory polymers (SMPs) are being investigated as alternative candidate materials for endovascular applications such as thrombectomy, primarily because SMPs exhibit recoverable deformations up to 100 times greater than those reported for SMAs $[13,16,17]$. Consequently, many SMPbased endovascular devices are capable of undergoing the significant shape changes necessary for catheter delivery [11, 18-22]. This property enables the exploration of novel device designs that have the potential to address the issues with commercially available thrombectomy devices, for example, difficult maneuverability. For example, Buckley et al. [23] proposed a design that is crimped to a cylinder for catheter delivery and is actuated to a flower shape distal to the occlusion such that only the edge of the "petals" is in contact with the vessel during treatment minimizing device-vessel contact points.

While SMPs generally exhibit maximum recoverable forces less than 1/100 times the recovery force of SMAs, another advantage is tunability of thermomechanical properties including recovery force, modulus, actuation temperature (for thermally actuated SMPs), and recoverable strain to meet the material demands of various applications. One effective, demonstrated method of tailoring thermomechanical properties of SMPs is controlling crosslink density [24, 25]. Increasing crosslink density of SMP systems has been generally shown to increase recovery stress $[11,26,27]$. At the same time, however, increasing crosslink density can also have undesired effects such as increased brittleness and decreased strain capacity [28].

The objective of this study is to evaluate the feasibility of fabricating SMP-based thrombectomy devices from crosslinked SMP acrylates by (1) finding the crosslink density that results in increased recovery stress without compromising the strain capacity necessary for crimping and actuation and (2) determining whether the resulting thermomechanical properties would be suitable for thrombectomy in a bench-top model.

\section{Materials and Methods}

After finalizing the device design, the deformation of the device was modeled via finite element analysis (FEA) to estimate maximum strains. Then, a system of crosslinked acrylic SMPs was designed with varying crosslink densities and with strain capacities greater than the maximum strains predicted by FEA. Devices were subsequently machined and subjected to force-monitored crimping and constrained recovery, and finally blood clot removal experiments were performed in a bench-top thrombotic model.

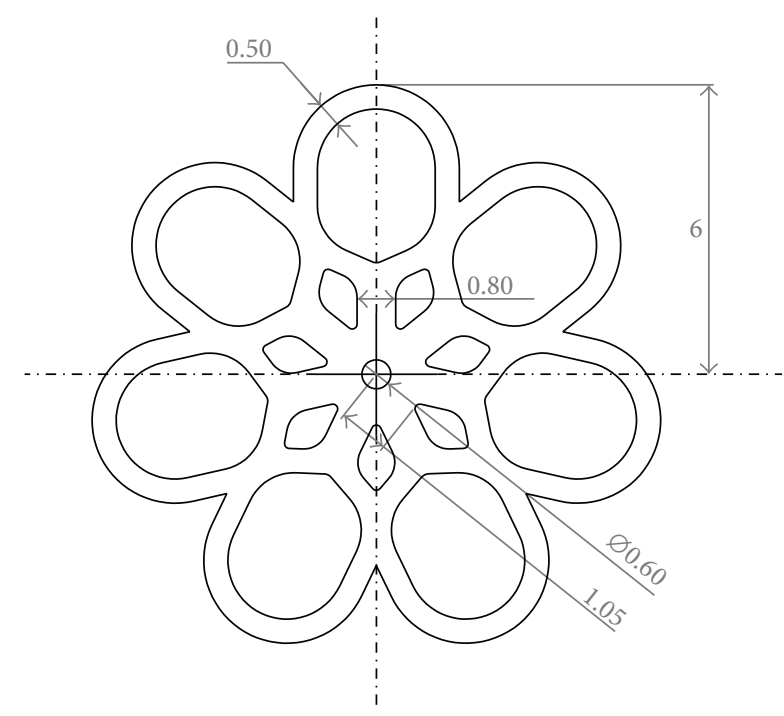

FIGURE 1: Flower-shaped thrombectomy device designed in SolidWorks with dimensions in $\mathrm{mm}$. This design was adapted from an original thrombectomy device proposed by Buckley et al. [23].

2.1. Device Design. Flower-shaped devices were designed in SolidWorks based on the geometry proposed by Buckley et al. [23]. Modifications to the design were necessary to prevent portions of the device folding over themselves during crimping and to reduce potential areas of stress concentrations. In order to better visualize the devices during testing, we designed them to be 4 times larger than they would be for in vivo testing. The design used in this study is depicted in Figure 1.

2.2. Finite Element Analysis Simulations. The device design was imported from the SolidWorks file created to fabricate the device (see Figure 1), and the crimping funnel (small inner diameter $=3.5 \mathrm{~mm}$, large inner diameter $=12.5 \mathrm{~mm}$ ) and ball (outer diameter $=2 \mathrm{~mm}$ ) were created in Abaqus as analytical rigid parts. The device was modeled using 1/14th symmetry in a cylindrical coordinate system. The device was meshed using approximately 12000 linear, 3D, hybrid brick elements $(\mathrm{C} 3 \mathrm{D} 8 \mathrm{H})$ and was modeled as an isotropic MooneyRivlin material with coefficients of $\mathrm{C}_{10}=3.06865 \mathrm{MPa}$ and $\mathrm{C}_{01}=-0.94798 \mathrm{MPa}$. These coefficients were obtained by analyzing, using the material evaluator function in Abaqus, the tensile test data for each of the polymer compositions and averaging the resulting Mooney-Rivlin coefficients. Because the strain-which is dictated by the geometry change in passing through the funnel-of the thrombectomy device was the primary quantity of interest, efforts were not made to further optimize the constitutive response to the tensile test data. The nonlinear geometry feature was enabled for the simulation, and "hard" contact (i.e., no penetration) was assumed between the funnel and the device, the ball and the device, and the analytical planes and the device (to model self-contact in the loops during the crimping). A coefficient of friction of 0.04 was assigned between the funnel and the device based on a bench-top friction test between 
blocks of polytetrafluoroethylene (PTFE) and poly(methyl methacrylate) (PMMA). A value of 0.8 was assigned as the coefficient of friction between the device and the analytical planes (for self-contact) and between the ball and the device (to account for roughness of the ball) based on published data of the nominal coefficient of friction in acrylic [29]. The ball, device, and funnel were initially concentrically positioned, and then the ball was held spatially fixed while the funnel was moved to encompass the device.

2.3. Polymer Synthesis. The monomer benzyl methacrylate (BzMA), the crosslinker bisphenol A ethoxylate diacrylate $(\mathrm{Mn} \sim 512, \mathrm{BPA})$, and the photoinitiator 2,2-dimethoxy-2phenylacetophenone (DMPA) were purchased from Sigma Aldrich and used as received without further purification. This monomer and difunctional crosslinker combination, which is similar to that reported by Safranski and Gall [24], was selected because it enables the synthesis of a series of SMPs with tailorable crosslink densities and glass transitions above body temperature in the range of 65 to $75^{\circ} \mathrm{C}$. Benzyl methacrylate was also selected because Safranski and Gall [24] demonstrated that poly(benzyl methacrylate) thermoset SMPs have higher toughness than numerous other thermoset acrylics. Four thermoset acrylic BzMA-BPA copolymers containing $5,15,25$, and 35 mole $\%$ BPA and 0.5 weight $\%$ DMPA were prepared in $51 \times 76 \times 0.4 \mathrm{~mm}$ sheets by bulk UV curing. After massing, the monomer, crosslinker, and photoinitiator mixtures were injected between $51 \times 76 \mathrm{~mm}$ glass slides coated with Rain-X separated by $0.4 \mathrm{~mm}$ spacers and cured for 99 minutes using $365 \mathrm{~nm}$ UV irradiation inside a UVP CL-1000 crosslinking chamber. The cured thermoset films were then postcured at $130^{\circ} \mathrm{C}$ with vacuum at 1 torr for 12 hours and subsequently stored under desiccation.

2.4. Dynamic Mechanical Analysis. Dynamic mechanical analysis (DMA) experiments were carried out in tension using a TA Instruments Q800 dynamic mechanical analyzer and $4 \times 30 \times 0.4 \mathrm{~mm}$ rectangular specimens $(n=5)$. The rectangular specimens were machined with a $40 \mathrm{~W}$ Gravograph LS100 $\mathrm{CO}_{2}$ laser machining device using a $38.1 \mathrm{~mm}$ lens, a speed setting of 5 , a power setting of 10 , and a laser resolution of 1200 dots per inch. Specimens were cleaned with a methanol damp Kimwipe, dried at $90^{\circ} \mathrm{C}$ under vacuum at 1 Torr, and subsequently stored under desiccation prior to being tested. DMA experiments were carried out from -20 to $140^{\circ} \mathrm{C}$ in the DMA multifrequency/strain instrument mode using a frequency of $1 \mathrm{~Hz}$, a strain of $0.1 \%$, a preload force of $0.01 \mathrm{~N}$, a force track of $150 \%$, and a heating rate of $2^{\circ} \mathrm{C} / \mathrm{min}$. Data were recorded using TA Instruments Qseries software and analyzed using TA Instruments Universal Analysis software.

2.5. Tensile Testing. Uniaxial tensile testing experiments were conducted to failure on ASTM type V dog bone samples $(n=$ 5) using a dual-column Instron model 5965 tensile tester with a $500 \mathrm{~N}$ load cell, $1000 \mathrm{~N}$ high temperature pneumatic grips, and a temperature chamber thermally controlled by forced convection heating. The dog bone samples were cut using a

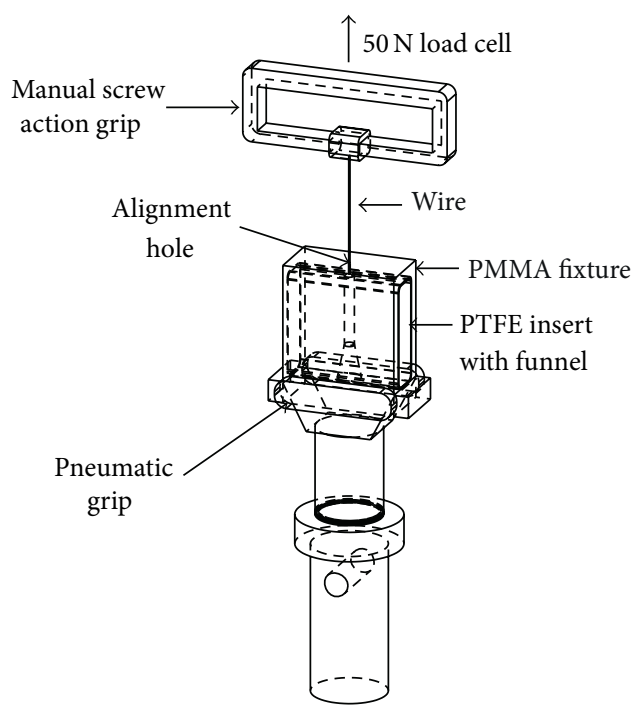

FIGURE 2: Sketch of custom-made apparatus for the crimping of the thrombectomy devices. The apparatus was designed so that it was compatible with the Instron tensile tester. Each device was inserted in the PTFE funnel, and after thermal equilibrium was achieved after 1 hour, the device was slid upwards by the movement of the crosshead connected to the manual screw action grip. The device was allowed to cool down in the narrow cylindrical feature of the PTFE insert, above the funnel.

$40 \mathrm{~W}$ Gravograph LS100 $\mathrm{CO}_{2}$ laser machining device with the same instrument parameters used to cut the rectangular DMA specimens. Specimens were cleaned with a methanol damp Kimwipe, dried at $90^{\circ} \mathrm{C}$ under vacuum at 1 Torr, and subsequently stored under desiccation prior to being tested. Specimen deformation was measured optically using an Instron Advanced Video Extensometer with a $60 \mathrm{~mm}$ fieldof-view lens. Specimens were heated to target temperatures under zero loads (unclamped bottom grip) and were held isothermally for 30 minutes to allow thermal equilibrium to be reached. The bottom grip was then clamped, and the strain-to-failure experiments were subsequently begun using a deformation rate of $10 \mathrm{~mm} / \mathrm{min}$. Data were recorded using Instron Bluehill 3 software.

2.6. Device Fabrication. The postcured $51 \times 76 \times 0.4 \mathrm{~mm}$ sheets of the four different copolymers were cut with the design pattern shown in Figure 1 utilizing the $40 \mathrm{~W}$ Gravograph LS100 $\mathrm{CO}_{2}$ laser machining device. The same instrument parameters were implemented as the ones used to cut the DMA and dog bone specimens. Devices were carefully cleaned with a methanol damp Kimwipe, dried at $90^{\circ} \mathrm{C}$ under vacuum at 1 Torr prior, and subsequently stored under desiccation prior to being tested.

2.7. Device Crimping. A custom fixture compatible with Instron tensile tester systems was fabricated with a minicomputer numerically controlled (CNC) milling machine (see Figure 2). It consisted of a removable portion made of PTFE with a funnel-like geometry on the inside and a stationary 


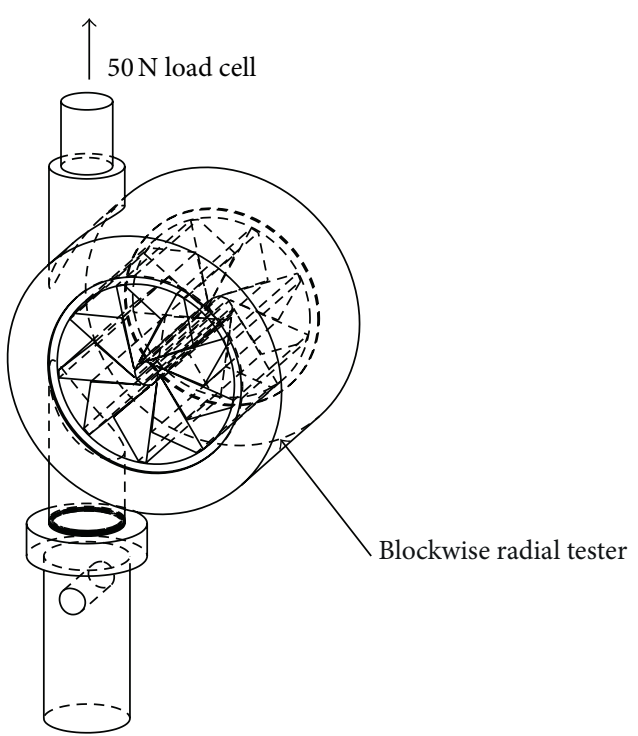

FIGURE 3: Sketch of Blockwise radial tester utilized in the constrained recovery experiments (not drawn to scale). The diameter enclosed by the blades was set with a high accuracy gage pin, and each device was inserted in its crimped configuration. The temperature of the blades was ramped from 30 to $55^{\circ} \mathrm{C}$, while the diameter of the radial tester was kept constant. As the thrombectomy device recovered its shape, it exerted a load onto the blades, which was sensed by the load cell.

portion made of PMMA that was attached to the tensile tester's bottom pneumatic grip. The maximum diameter of the funnel was $12.5 \mathrm{~mm}$ and it contracted gradually to $3.5 \mathrm{~mm}$ (the portion with the smallest diameter was $1 \mathrm{~cm}$ long and it served to fit the length of the crimped device and allow it to cool down). The stationary portion had a cap with a $0.3 \mathrm{~mm}$ hole machined with an excimer laser that helped center the wire that held the devices throughout the crimping process. This wire had $\sim 2 \mathrm{~mm}$ diameter ball of $96.5 \mathrm{Sn} 3.5 \mathrm{Ag}$ solder purchased from Indium Corporation at the tip to hold the devices as they were pulled during crimping. By inserting a thermocouple inside the funnel of the assembled crimping fixture, it was determined that in order to achieve the target temperature inside the funnel within 45 minutes the temperature chamber was required to be set $4^{\circ} \mathrm{C}$ higher. Thus, devices were allowed to thermally equilibrate inside the funnel for a minimum of 1 hour prior to testing. The tensile tester had a $50 \mathrm{~N}$ load cell, rated with a resolution of $0.00025 \mathrm{~N}$, and was set to extension mode at a strain rate of $5 \mathrm{~mm} / \mathrm{min}$. Data were recorded using Instron Bluehill 3 software. The crimping experiments were performed at temperatures corresponding to the mechanical transition temperatures, DMA loss modulus peak, and tan delta peak, of each copolymer's composition $(n=5)$.

2.8. Device Constrained Recovery. A commercially available Blockwise Engineering RJA62 radial stress tester compatible with Instron tensile tester systems with a $50 \mathrm{~N}$ load cell was utilized to perform constrained recovery measurements of

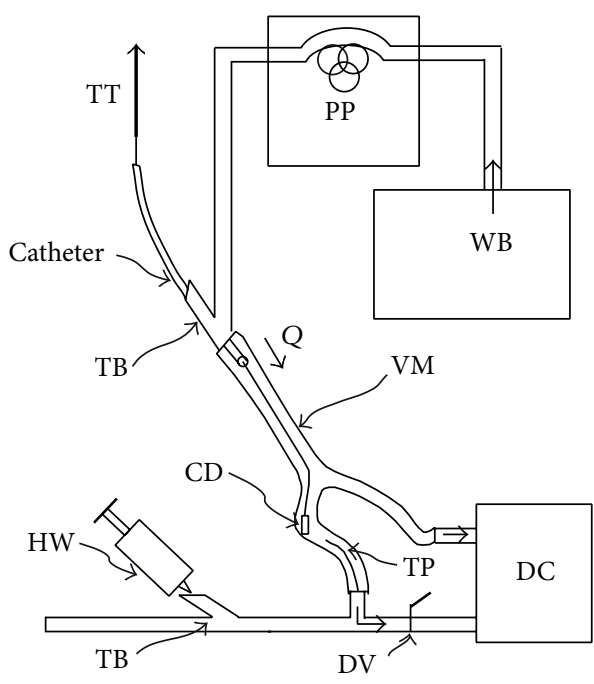

Figure 4: Bench-top thrombotic stroke model. WB: water bath $\left(37^{\circ} \mathrm{C}\right)$; PP: peristaltic pump; TT: tensile tester (extension rate $=$ $75 \mathrm{~mm} / \mathrm{min}) ; \mathrm{Q}$ : experimental flow rate $(=57 \mathrm{~mL} / \mathrm{min})$; TB: Touhy Borst valve; CD: crimped device location; VM: vessel model; TP: thermocouple probe; HW: hot water syringe; DV: discharge valve; DC: discharge container.

the crimped devices (see Figure 3). The radial tester temperature was ramped from $30^{\circ} \mathrm{C}$ to $55^{\circ} \mathrm{C}$ and the recovery stress of the devices that were previously crimped at loss modulus peak temperature was measured at $1 \mathrm{~Hz}$ using Instron Bluehill 3 software. A thermocouple was installed in close proximity of each device, and temperature was also recorded at $1 \mathrm{~Hz}$ using LabView. The diameter of the tester was kept constant at $3.75 \mathrm{~mm}$ after setting it with a high accuracy gage pin. The blade heating effects of the radial tester were accounted for by subtracting data measured with the empty tester from the data of all measured devices for the same temperature range.

2.9. Bench-Top Blood Clot Removal. A bench-top thrombotic stroke model shown in Figure 4 was constructed to test the feasibility of the SMP flower-shaped devices for blood clot hold during removal. The blood clots were prepared with bovine blood $(10 \mathrm{~mL})$, which was acquired from Vet Med Park, College Station, Texas. Barium sulphate (1g) and bovine thrombin (25 IU), both purchased from VWR International, were added to the bovine blood, and the mixture was injected into a silicone tube with $10 \mathrm{~mm}$ inner diameter. The mixture was gently agitated for about 5 minutes and was incubated at room temperature for at least 1 hour prior to testing [30]. Blood clots of roughly $2 \mathrm{~cm}$ in length were cut with a scalpel.

Each crimped device was inserted into the silicone bifurcated vessel model (purchased from Shelley Medical Imaging Technologies, Ontario, Canada) followed by a blood clot. Water at $37^{\circ} \mathrm{C}$ was pumped into the main vessel segment (lumen diameter $=8 \mathrm{~mm}$ ) at a flow rate of $57 \mathrm{~mL} / \mathrm{min}$ via a peristaltic pump. The in vivo dynamically similar flow rate via the matching of the Reynolds number that corresponds to the experimental flow rate is within the range of flow rates recorded in the middle cerebral artery, a common site 


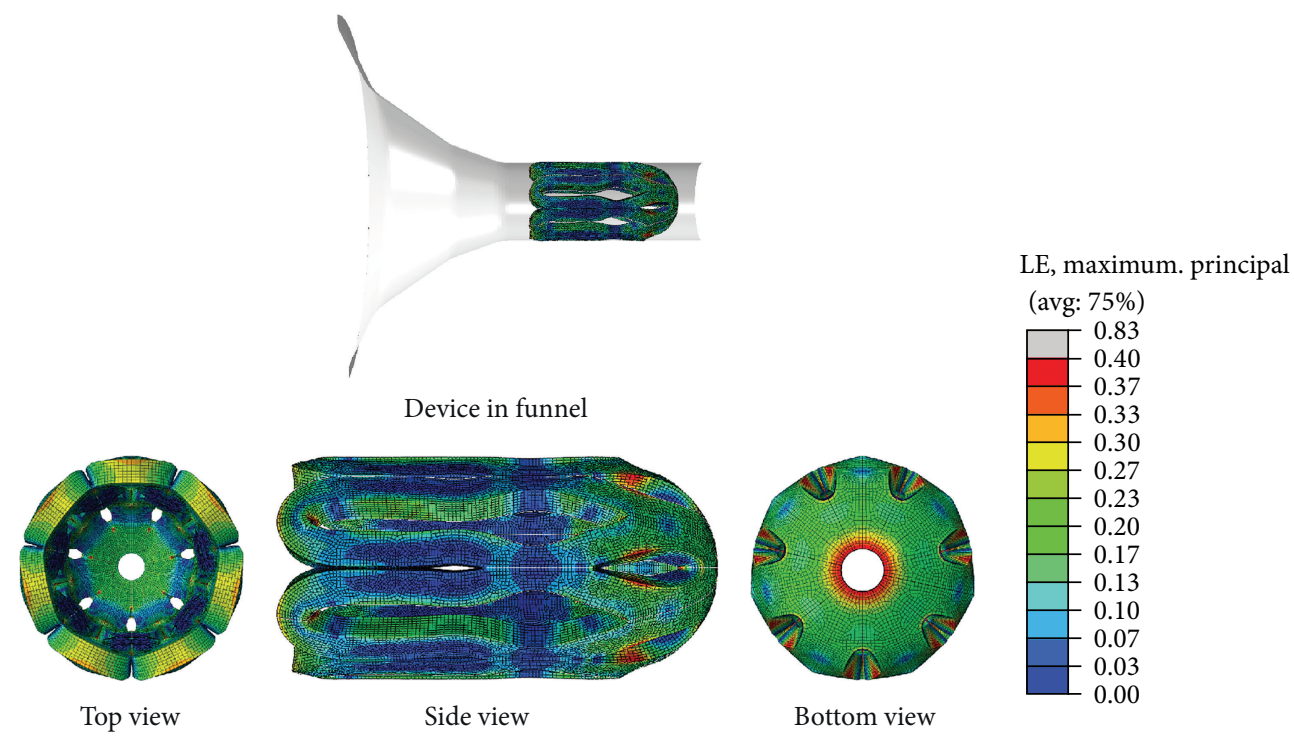

FIGURE 5: Estimates in the thrombectomy device for the principal logarithmic strains during the crimping procedure. The maximum principal strains are approximately $40 \%$ and are located on the struts of the bottom loops of the device as well as near the center circle.

for thromboembolic occlusion in the neurovasculature [31]. Each device was actuated by injecting water near boiling temperature with a syringe while shutting the valve that connects one of the bifurcations of the vessel model to the discharge container. The device was attached to a guide wire, which was connected to a Synergy MTS tensile tester through a catheter. To ensure the repeatability of device testing, the crosshead of the tensile tester pulled each device at an extension rate of $75 \mathrm{~mm} / \mathrm{min}$ to remove the blood clot. The temperature before and during actuation was recorded at $1 \mathrm{~Hz}$ by placing a thermocouple near the location of the device.

\section{Results}

3.1. FEA Simulations. Finite element simulations were performed using Abaqus 6.12-1 finite element software to estimate the strains imposed on the thrombectomy device during the crimping procedure. The geometry of the thrombectomy device, adapted from Buckley et al. [23], was imported from SolidWorks, and the additional parts necessary for the crimping-specifically, a funnel with a final inner diameter of $3.5 \mathrm{~mm}$ and a rigid sphere with a diameter of $2 \mathrm{~mm}-$ were created as analytical rigid parts in Abaqus. The ball was placed in contact with the thrombectomy device and the funnel was moved so as to crimp the device around the rigid ball. This motion mimicked that of pulling the device through the funnel using a wire that was terminated by a $2 \mathrm{~mm}$ ball. Figure 5 shows the strain contours on the device when it was in the final crimped state inside the funnel. In this figure, the device, which was modeled using 1/14th symmetry about the longitudinal axis, was mirrored and then patterned 7 times to be displayed in its entirety. The maximum principal strains were approximately $0.35-0.4 \mathrm{~mm} / \mathrm{mm}$ and were located at the base of the device near the circular cutout as well as on the struts of the innermost loops. The strain concentrations
TABLE 1: Rubbery modulus and mechanical transition temperature values.

\begin{tabular}{lccc}
\hline Composition & $\begin{array}{c}\text { Rubbery } \\
\text { modulus } \\
(\mathrm{MPa})\end{array}$ & $\begin{array}{c}\text { Loss modulus peak } \\
\text { temperature } \\
\left({ }^{\circ} \mathrm{C}\right)\end{array}$ & $\begin{array}{c}\text { Tan delta peak } \\
\text { temperature } \\
\left({ }^{\circ} \mathrm{C}\right)\end{array}$ \\
\hline $5 \% \mathrm{BPA}$ & $1.67 \pm 0.18$ & $62.3 \pm 0.16$ & $72.3 \pm 0.16$ \\
$15 \% \mathrm{BPA}$ & $5.92 \pm 0.08$ & $53.6 \pm 0.17$ & $66.9 \pm 0.16$ \\
$25 \% \mathrm{BPA}$ & $11.0 \pm 0.32$ & $50.8 \pm 0.25$ & $62.8 \pm 0.24$ \\
$35 \% \mathrm{BPA}$ & $15.6 \pm 1.02$ & $50.8 \pm 0.11$ & $61.5 \pm 0.12$ \\
\hline
\end{tabular}

near the center hole of the device were a result of the large deformation necessary to bend the petals upward, and the concentrations on the struts were a result of the twisting necessary to align portions of the petals for insertion into the funnel.

3.2. Material Properties of Copolymers. Plots of storage modulus, loss modulus, and tan delta for acrylic SMP samples containing 5, 15, 25, and 35 mole $\%$ BPA are provided in Figures 6(a)-6(c), and numerical values for rubbery modulus, loss modulus peak temperatures, and tan delta peak temperatures are provided in Table 1 . Rubbery moduli were defined as the lowest value in the rubbery storage modulus curves for all four chemical compositions. As BPA crosslinker was increased from 5 to 35 mole\%, rubbery modulus increased from 1.6 to $15.6 \mathrm{MPa}$. Loss modulus peak temperatures were in the range of 50.8 to $62.3^{\circ} \mathrm{C}$, tan delta peak temperatures were in the range of 61.5 to $72.3^{\circ} \mathrm{C}$, and both loss modulus peak temperatures and tan delta peak temperatures decreased with increasing BPA crosslinker composition. Although increasing crosslink density often results in increased glass transition temperature in thermoset polymers, the decrease in glass transition with increasing 


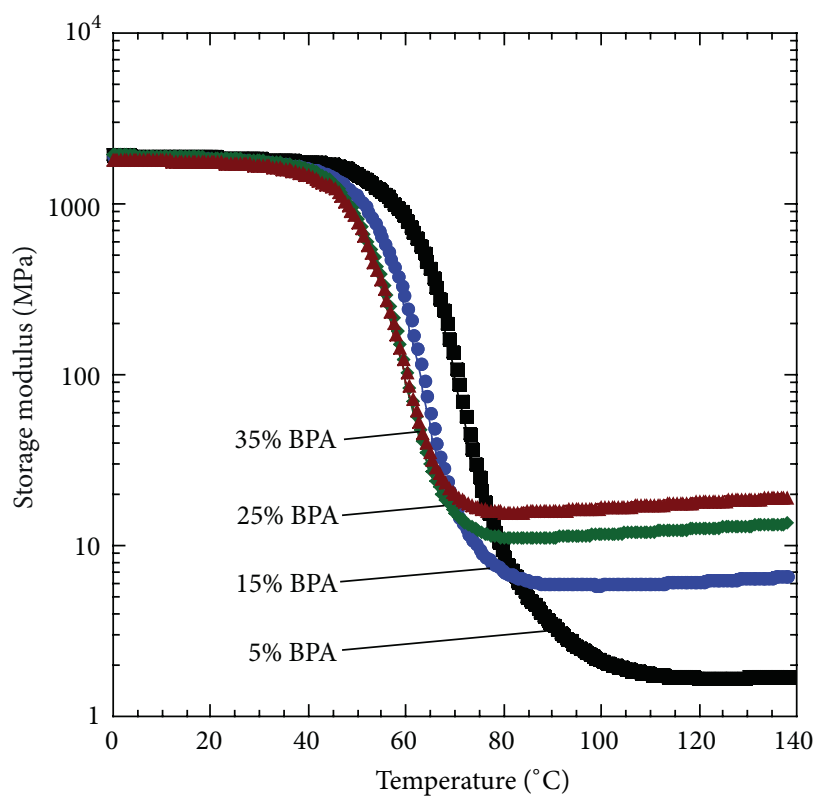

(a)

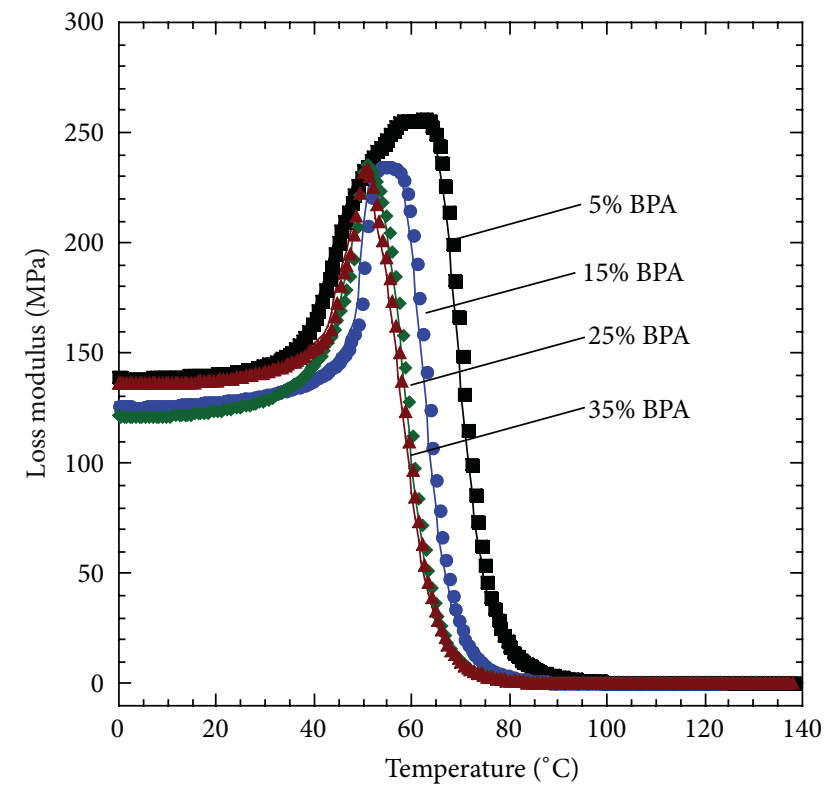

(b)

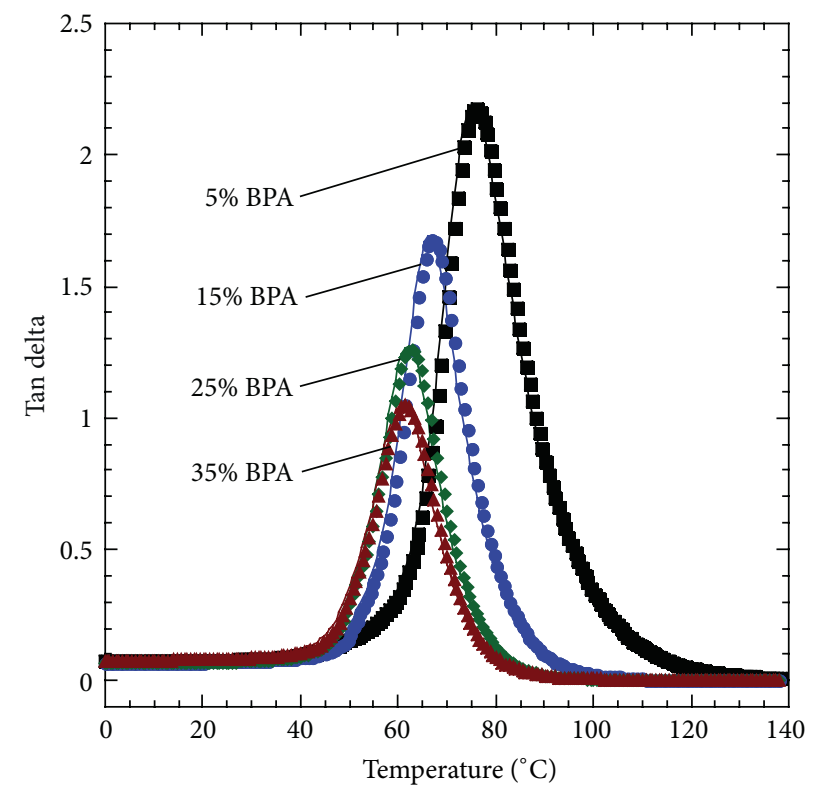

(c)

Figure 6: Dynamic mechanical response of the four copolymers, storage modulus (a), loss modulus (b), and tan delta (c). In panel (a), the lowest point of the curve (i.e., the rubbery modulus) increased as a function of increasing crosslinker. Additionally, an increase in the temperature that corresponds to loss modulus peak and tan delta peak in panels (b) and (c), respectively, was observed as a result of increasing crosslinker.

BPA composition in this study was expected because the BPA crosslinker contains flexible polyethylene oxide repeat units, which have a competing effect with crosslink density on glass transition. It was this competing effect that was used to enable the synthesis of four SMPs with significantly different crosslink densities and similar glass transition temperatures.

Strain-to-failure experiments were performed on all four BPA composition samples at both loss modulus peak and tan delta peak temperatures. All stress/strain results are shown in
Figures 7(a) and 7(b), and average stress-at-failure, strain-tofailure, and toughness (area under the stress/strain curves) data is listed in Table 2. For strain-to-failure experiments conducted at loss modulus peak temperatures, increasing the BPA crosslinker from 5 to 35 mole\% resulted in an average stress-at-failure increase from 11.9 to $23.0 \mathrm{MPa}$ and an average strain-to-failure decrease from 1.43 to $0.48 \mathrm{~mm} / \mathrm{mm}$. For strain-to-failure experiments conducted at tan delta peak temperatures, increasing BPA composition resulted in an 
TABLE 2: Rubbery modulus and mechanical transition temperature values.

\begin{tabular}{lcccc}
\hline & Composition & $\begin{array}{c}\text { Strain-to-failure } \\
(\mathrm{mm} / \mathrm{mm})\end{array}$ & $\begin{array}{c}\text { Stress-at-failure } \\
(\mathrm{MPa})\end{array}$ & $\begin{array}{c}\text { Toughness } \\
\left(\mathrm{MJ} / \mathrm{m}^{3}\right)\end{array}$ \\
\hline \multirow{4}{*}{$T$ temperature at loss modulus peak } & $5 \% \mathrm{BPA}$ & $1.43 \pm 0.0985$ & $11.9 \pm 2.14$ & $8.99 \pm 1.72$ \\
& $15 \% \mathrm{BPA}$ & $0.773 \pm 0.0906$ & $14.2 \pm 1.51$ & $6.21 \pm 0.992$ \\
& $25 \% \mathrm{BPA}$ & $0.609 \pm 0.119$ & $13.2 \pm 1.07$ & $3.96 \pm 0.747$ \\
& $35 \% \mathrm{BPA}$ & $0.475 \pm 0.0957$ & $23.0 \pm 4.15$ & $6.38 \pm 1.79$ \\
\hline \multirow{3}{*}{$T$ temperature at tan delta peak } & $5 \% \mathrm{BPA}$ & $1.41 \pm 0.254$ & $2.75 \pm 0.338$ & $1.49 \pm 0.296$ \\
& $15 \% \mathrm{BPA}$ & $0.590 \pm 0.182$ & $2.87 \pm 0.254$ & $0.697 \pm 0.169$ \\
& $25 \% \mathrm{BPA}$ & $0.357 \pm 0.0354$ & $4.09 \pm 0.251$ & $0.647 \pm 0.0723$ \\
& $35 \% \mathrm{BPA}$ & $0.376 \pm 0.0879$ & $7.73 \pm 1.56$ & $1.24 \pm 0.316$ \\
\hline
\end{tabular}

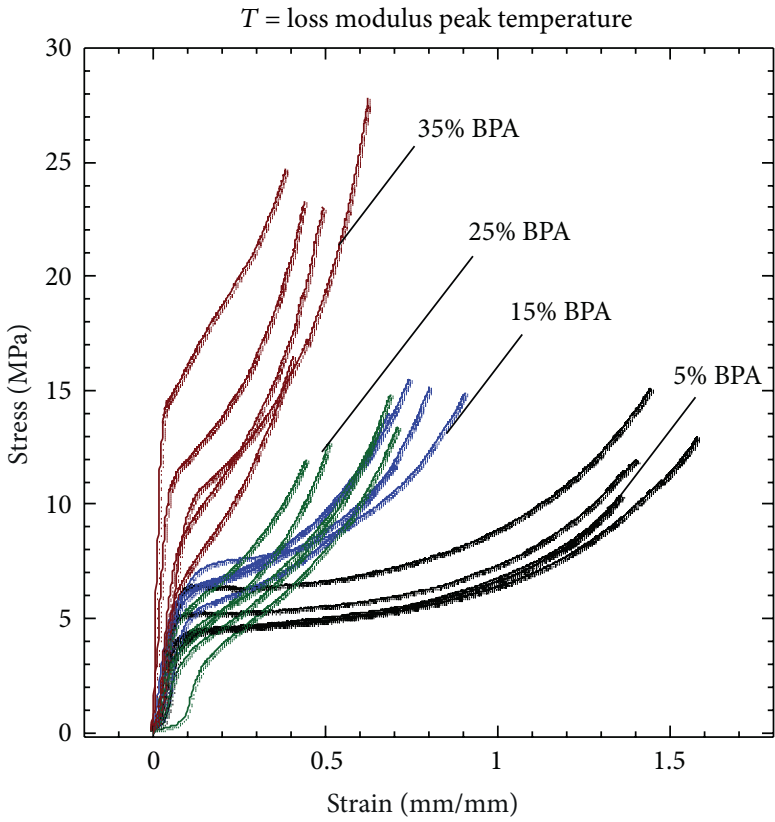

(a)

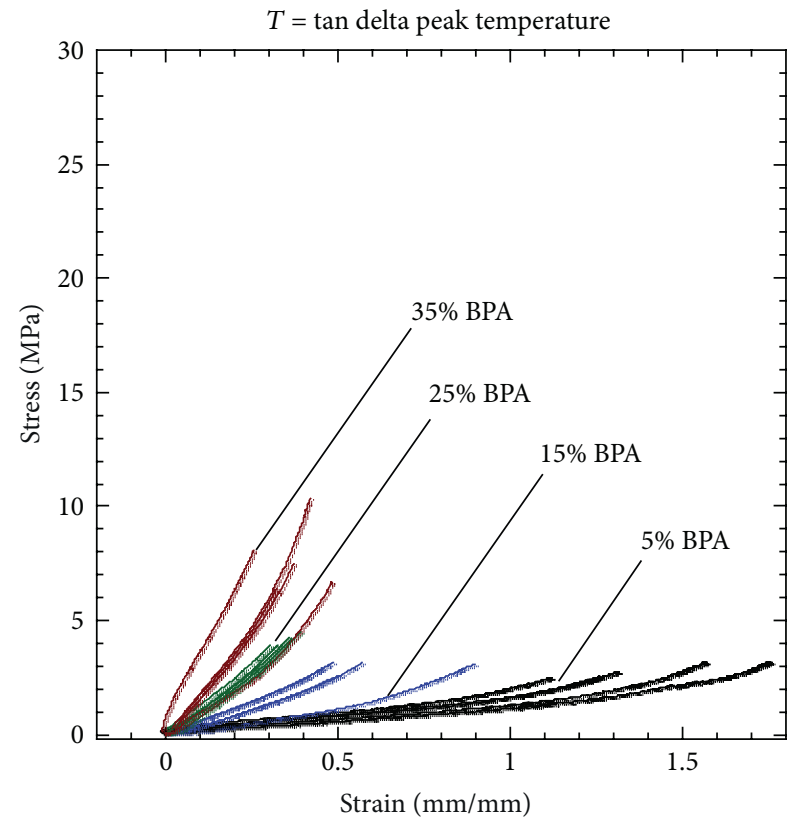

(b)

FIGURE 7: Tensile properties of the four copolymers measured at each copolymer's loss modulus peak (a) and tan delta peak (b) temperatures. In both temperatures, the strain capacity of the copolymers decreased as a result of increasing crosslinker; however, a more brittle response was observed at tan delta peak temperatures.

average stress-at failure increase from 2.8 to $7.7 \mathrm{MPa}$ and an average strain-to-failure decrease from 1.41 to $0.37 \mathrm{~mm} / \mathrm{mm}$. For both the loss modulus peak temperature and tan delta peak temperature strain-to-failure series, toughness decreased as BPA composition was increased from 5 to 15 to $25 \mathrm{~mole} \%$ and then increased for the 35\% BPA samples. One possible explanation for this increase in toughness for the most highly crosslinked samples is that bisphenol A groups have been shown to be capable of undergoing $\pi$ $\pi$ stacking, which increases toughness in materials such as poly(bisphenol A carbonate) [32]. It is possible that, at high enough BPA compositions, $\pi-\pi$ stacking can become predominant enough to improve toughness.

3.3. Device Crimping. A total of five devices were crimped for each of the four BPA compositions. Figures 8(a) and 9(a) show plots of force versus extension during crimping at loss modulus peak temperatures and tan delta peak temperatures, respectively. Figures $8(\mathrm{~b})$ and $9(\mathrm{~b})$ show images of the top, side, and bottom views of crimped 35 mole\% BPA devices at the two respective crimping temperatures. The crimping temperature had a significant effect on both the magnitude of the force required for crimping and on the propensity for device failure during crimping. For devices crimped at loss modulus peak temperature, the maximum average crimping force increased from 0.41 to $1.05 \mathrm{~N}$ as BPA composition increased from 5 to 35 mole\%. For devices crimped at tan delta peak temperature, the maximum average crimping force increased from 0.10 to $0.58 \mathrm{~N}$ as BPA composition increased from 5 to 35 mole\%. None of the devices crimped at loss modulus peak temperature failed upon crimping. On the contrary, the devices crimped at tan delta peak temperature 


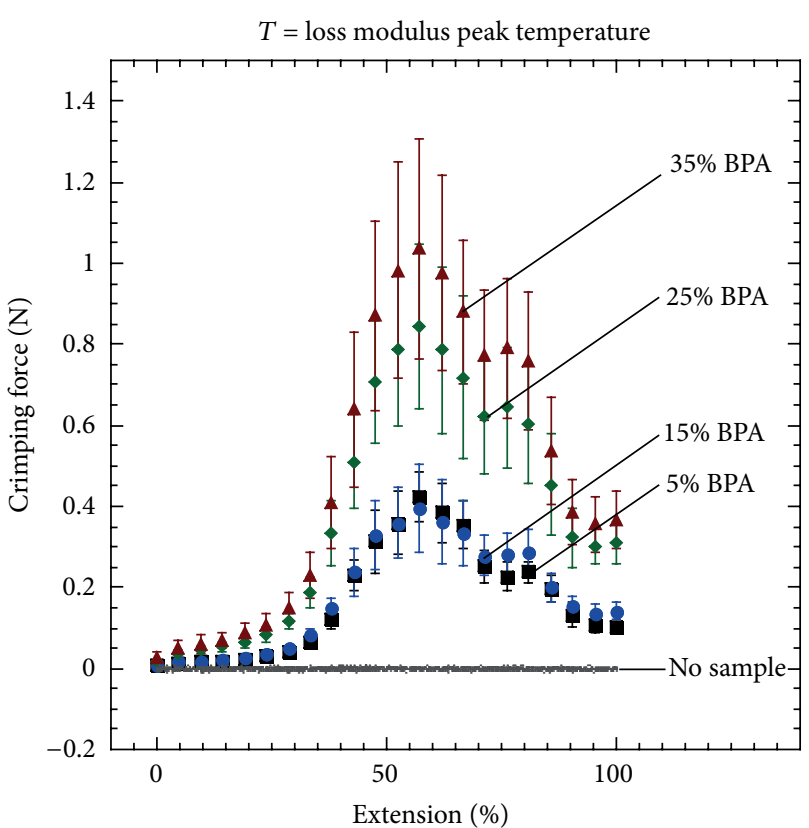

(a)

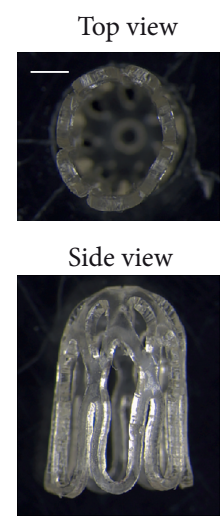

Bottom view

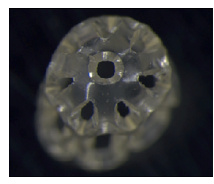

(b)

FIGURE 8: Force measurements of devices crimped at loss modulus peak temperature (a). Example of one device with 35 mole\% BPA crimped at loss modulus peak temperature (scale bar $=1 \mathrm{~mm})(\mathrm{b})$. Images were taken at $2.5 \mathrm{x}$ magnification.

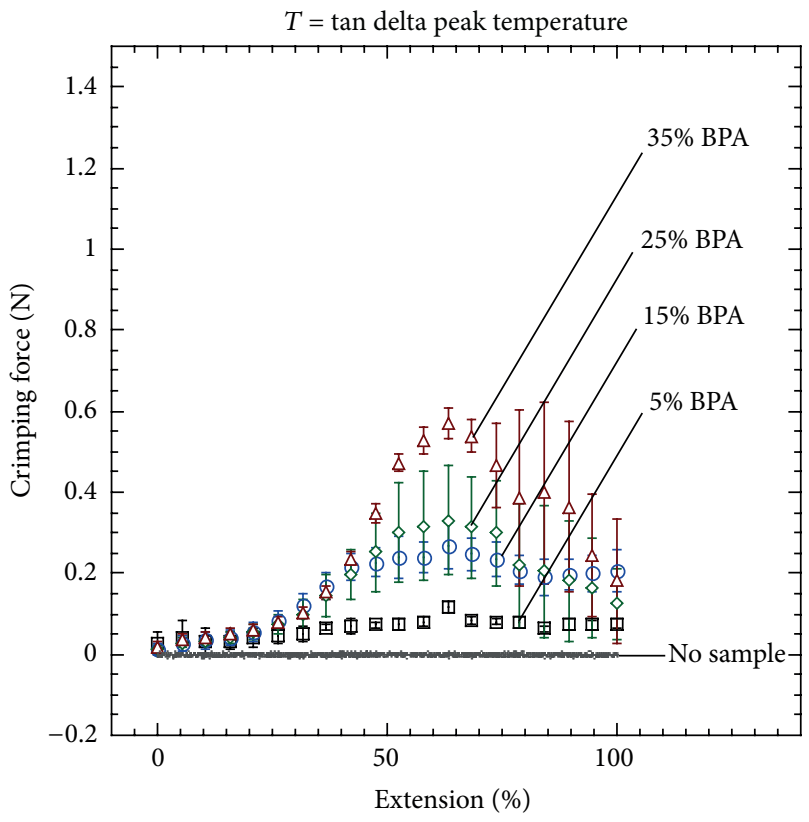

(a)

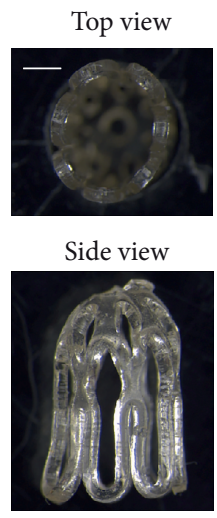

Bottom view

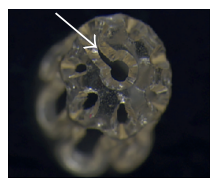

(b)

FIGURE 9: Force measurements of devices crimped at tan delta peak temperature (a). Example of one device with 35 mole\% BPA crimped at $\tan$ delta peak temperature (scale bar $=1 \mathrm{~mm}$ ) (b). Images were taken at $2.5 \mathrm{x}$ magnification. White arrow points at a common site for failure.

were much more susceptible to failure during crimping: for the $5,15,25$, and 35 mole\% BPA samples, the number of devices that failed was 1, 2, 3, and 5, respectively. Most failure locations consistently occurred at the bases of the devices and appeared to initiate at the edges of the center holes, as shown in Figure 9(b).
3.4. Device Constrained Recovery. Because of the significant device failures that occurred during crimping at tan delta peak temperatures, only devices crimped at loss modulus peak temperatures were subjected to constrained recovery tests. Five devices were tested for each BPA composition. In Figure 10, a plot of average recovery stress versus temperature 


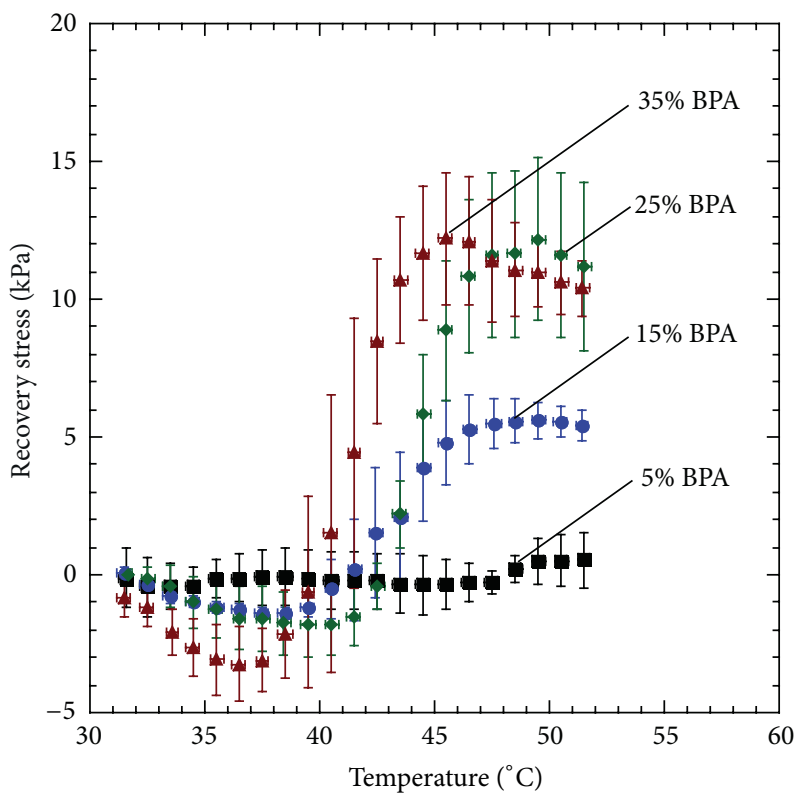

FIGURE 10: Recovery stress of thrombectomy devices during constrained recovery. Increasing the crosslinker amount resulted in an increase in recovery stress measured under constrained conditions. However, for the two highest crosslinked compositions, the recovery stress was not significantly different, because failures were observed in both compositions but were more prevalent in devices with 35 mole\% BPA.

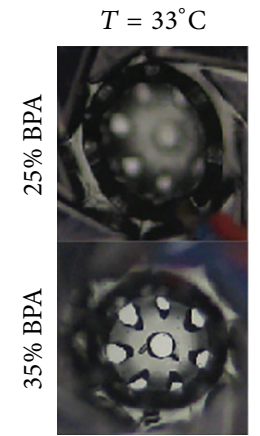

$T=31^{\circ} \mathrm{C}$

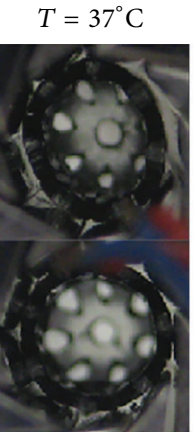

$T=38^{\circ} \mathrm{C}$

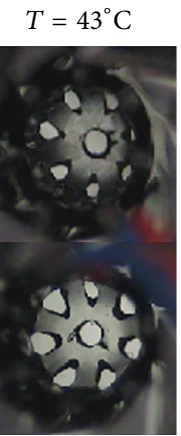

$T=43^{\circ} \mathrm{C}$

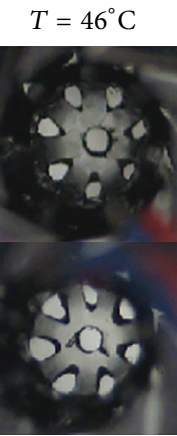

$T=47^{\circ} \mathrm{C}$

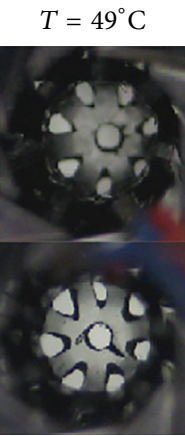

$T=50^{\circ} \mathrm{C}$

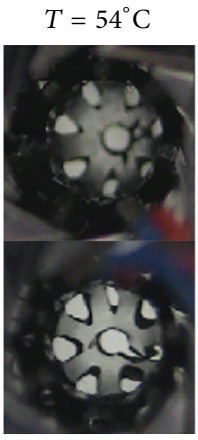

$T=53^{\circ} \mathrm{C}$

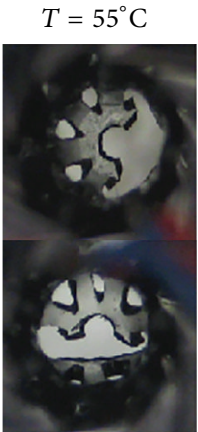

$T=55^{\circ} \mathrm{C}$

FIGURE 11: Crack development in devices of each composition (i.e., 25 and 35 mole\% BPA) during constrained recovery test at various temperature points as the device was recovering its primary shape.

is shown for devices with varying BPA composition. As BPA composition was increased from 5 to $35 \mathrm{~mole} \%$, average recovery stress increased from 0.526 to $12.2 \mathrm{kPa}$. It is notable that during the constrained recovery tests, two out of the five 25 mole\% BPA devices and four out of the five 35 mole\% BPA devices developed cracks and subsequently broke. Images of crack development at different temperature points during constrained recovery of 25 and 35 mole\% BPA samples are shown in Figure 11.

3.5. Blood Clot Removal Experiments. Three 5 and 15 mole\% BPA devices were subjected to blood clot removal experiments with flow. In order to better simulate in vivo conditions, an experimental flow rate of $57 \mathrm{~mL} / \mathrm{min}$ was chosen. This flow rate is equivalent to $113 \mathrm{~mL} / \mathrm{min}$ after dynamic similarity via matching the Reynolds number, which is within the range of flow rates recorded in the middle cerebral artery, a common site for thromboembolic occlusion in the neurovasculature [31]. Because the 25 and 35 mole\% BPA devices developed cracks during recovery under constrained conditions, they were not considered for the blood clot removal experiments. Images of the thrombectomy experiments for a 15 mole $\%$ BPA device and a diagram of the silicone vascular model used in the experiments are provided in Figure 12. To demonstrate that the crimped devices could maintain their crimped geometries under physiological conditions, they were first immersed in $37^{\circ} \mathrm{C}$ water and positioned past the bovine blood clot in the silicone vessel model, as pictured in Figure 12(a). After holding at $37^{\circ} \mathrm{C}$ to demonstrate shape fixity for 4 $5 \mathrm{~min}$, the water temperature was elevated to $\sim T_{g}+15{ }^{\circ} \mathrm{C}$ (maximum recorded temperature: $77^{\circ} \mathrm{C}$ ) over the course of $45 \mathrm{~s}$ by injecting water near boiling temperature to the flow 


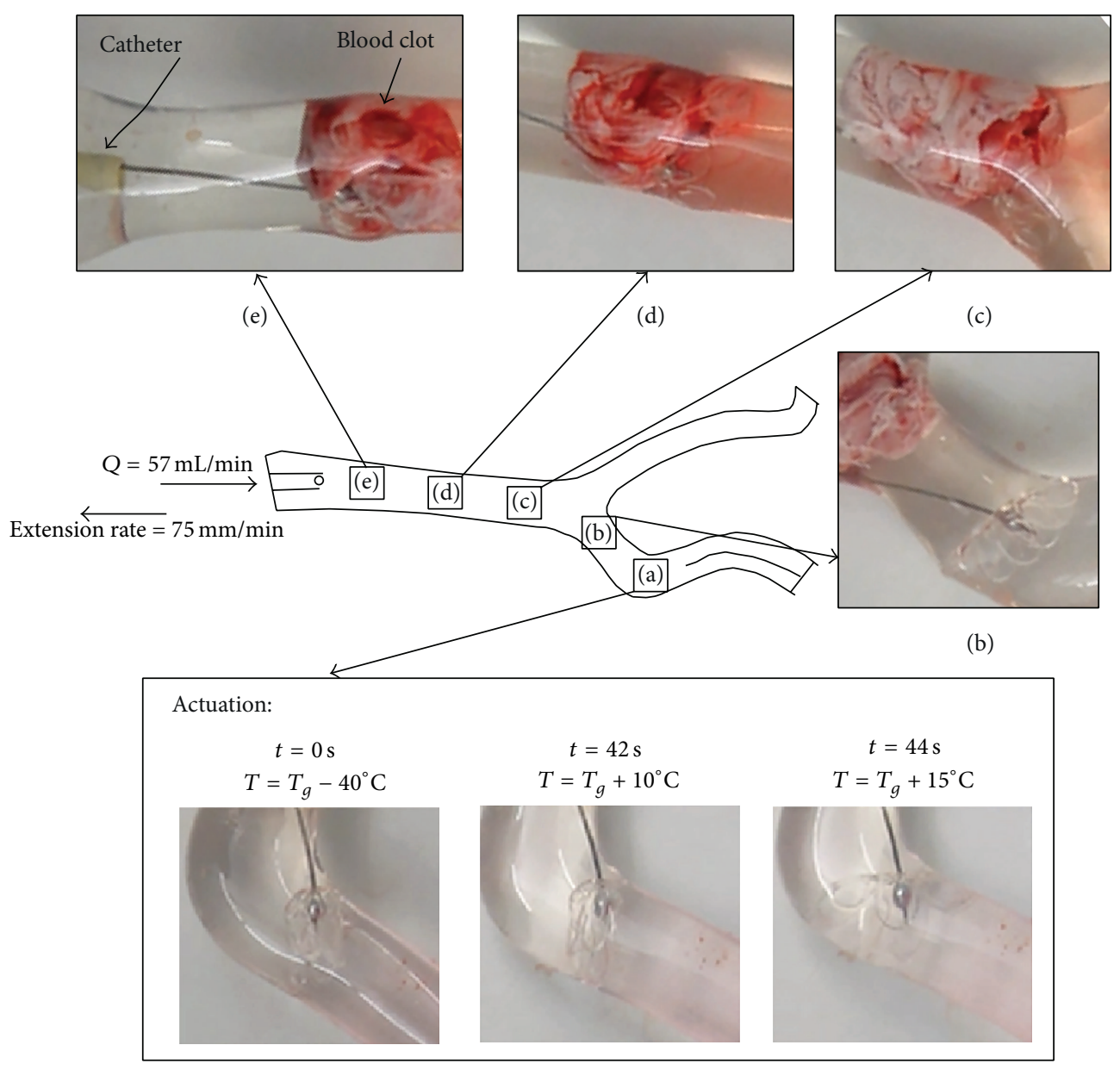

(a)

Figure 12: Actuation and clot removal with 15 mole\% BPA device. Q: experimental flow rate (=57 $\mathrm{mL} / \mathrm{min})$. Panel (a) shows the device during actuation as the hot water was injected. Panels (b)-(e) depict the actuated thrombectomy device as it is withdrawn by the tensile tester successfully moving the blood clot from the occluded vessel (panel (b)) to the location of the catheter (panel (e)).

system. The benefit of increasing crosslink density on device blood clot removal was demonstrated: $0 / 3$ of the 5 mole $\%$ BPA devices resulted in a successful extraction, while $2 / 3$ of the 15 mole\% BPA devices resulted in a successful blood clot extraction (i.e., the devices were able to move the blood clot from its origin at the bifurcation pictured in Figure 12(b) to the catheter tip at the end of the vasculature model, pictured in Figure 12(e)).

\section{Discussion}

The motivation for this study is the need for a SMP-based thrombectomy device that can exhibit sufficient recovery stress to reduce the likelihood of blood clot dislodgement during thrombectomy, while also being able to undergo sufficient deformation for catheter delivery. Thrombectomy is a promising treatment technique for the $\sim 97 \%$ of ischemic stroke patients who are not eligible to receive tPA, the only FDA-approved drug for the treatment of ischemic stroke $[2,6]$.
Given the geometry of the device, recovery stress plays an important role in achieving blood clot entrapment and successful removal. The devices tested in the bench-top thrombotic stroke model in this study consisted of 5 and 15 mole $\%$ BPA. The average recovery stress of the 15 mole $\%$ BPA devices was roughly one order of magnitude higher than that of the 5 mole\% BPA devices. This positive correlation between crosslink density and recovery stress in SMPs has been reported in numerous previous studies [11, 26, 27]. In an ideal rubber, elastic modulus is inversely proportional to the average molecular weight between crosslinks, so a more highly crosslinked rubber will have a higher stiffness than a more lightly crosslinked rubber. Consequently, more energy is required to achieve a specific deformation in a more highly crosslinked rubber than in a more lightly crosslinked rubber. Since the energy required to achieve these deformations is metastably stored when thermally actuated SMPs are strained and then cooled below their thermal transition regions, the force exerted by an SMP during recovery is consequently higher for a more highly crosslinked SMP [11, 25-27, 30]. 
None of the 5 mole\% BPA devices (0/3) exerted enough recovery stress to hold the blood clot in our bench-top thrombotic stroke model, while $2 / 3$ of the 15 mole\% BPA devices did retain the blood clot as it was being removed.

The goal of varying crosslink density in this study was to increase device recovery stress for improved blood clot hold. However, increased crosslink density also had a negative impact on device mechanical integrity: the majority of the 25 and 35 mole\% BPA samples did not endure the constrained recovery experiments. The temperature at which the devices were crimped also played an important role in device integrity. The strain-to-failure data in Figure 3 shows that the stress required to deform the specimens to specific strains decreased with increasing temperature for all compositions. Thus, it was expected that the forces required for crimping at higher temperatures (tan delta peak temperatures) were lower than those required for crimping at lower temperatures (loss modulus peak temperatures). Also, significant failure rates occurred during crimping at tan delta peak temperatures, while no failures occurred during crimping at loss modulus peak temperatures. This trend in failure during crimping most likely occurred because the samples were in higher toughness states at loss modulus peak temperatures than at tan delta peak temperatures (see Table 2). The devices that were more prone to failure at tan delta peak temperatures were the ones that exhibited strain-to-failure values below $0.4 \mathrm{~mm} / \mathrm{mm}$, and all failures originated at the base of the devices. This failure location is in accordance with FEA simulation predictions, which indicate that the bases of the devices are subjected to high localized strains within the range of 0.35 and $0.4 \mathrm{~mm} / \mathrm{mm}$. These localized strains, in conjunction with material limitations and possible machining defects, most likely caused crack initiations, which then led to device failures.

For the devices that were successfully crimped, the recovery stress under constrained conditions increased with increasing crosslink density. Nonetheless, some of the devices with 25 and 35 mole\% BPA, which had rubbery moduli greater than $10 \mathrm{MPa}$, failed during constrained recovery. In a similar manner to the findings in this study, Safranski and Gall [24] reported that for acrylic SMPs with rubbery moduli greater than $10 \mathrm{MPa}$ the crosslinking dominates the large strain mechanical properties of the network, and a relatively brittle response is observed. This pronounced brittle response in addition to machining defects may be the reason for failures in the devices with higher crosslink densities during constrained recovery.

Full constrained recovery experimentation represents a worst-case condition, but it is of great importance for a device such as the SMP thrombectomy device in this study. The pressure-strain elastic modulus of the common carotid artery, for example, is reported to be on the order of $55 \mathrm{kPa}$ for healthy patients [33]. However, as patients' age and arteries become more diseased, this value has been shown to increase to $\sim 165 \mathrm{kPa}$ [34]. Simply testing an actuating thrombectomy device in a silicone vessel model alone and neglecting to perform constrained recovery experiments could result in device failures such as the ones observed during the constrained recovery experiments in this study to remain unnoticed because a silicone vessel model is generally more compliant than a diseased artery. Thus, constrained recovery analysis should be performed a priori to avoid fatal complications that would probably only come into play in a more realistic environment, such as a diseased artery in a stroke patient.

\section{Conclusions}

We have reported an acrylic SMP system with glass transitions above body temperature in the range of 65 to $75^{\circ} \mathrm{C}$ with tailorable recovery stresses that were controlled by varying crosslink density. As expected, the increases in recovery stress that came with increasing crosslink density also resulted in reduced strain capacity and increased brittleness, which compromised the mechanical integrity of the devices during crimping and actuation. Thus, our results demonstrate that SMP materials with the highest rubbery moduli are not necessarily the best for applications requiring large deformations. From the four different material compositions evaluated, devices with 15 mole\% BPA gave the most favorable outcome. However, only $2 / 3$ of the devices of this composition were able to retain the blood clot in the bench-top experiment, suggesting that the system of acrylic SMPs presented in this study is not suitable for this application.

\section{Conflict of Interests}

The authors declare that there is no conflict of interests regarding the publication of this paper.

\section{References}

[1] D. Lloyd-Jones, R. Adams, M. Carnethon et al., "Heart disease and stroke statistics-2009 update. A report from the American heart association statistics committee and stroke statistics subcommittee," Circulation, vol. 119, no. 3, pp. 480-486, 2009.

[2] L. G. Stead, R. M. Gilmore, M. F. Bellolio, A. A. Rabinstein, and W. W. Decker, "Percutaneous clot removal devices in acute ischemic stroke: a systematic review and meta-analysis," Archives of Neurology, vol. 65, no. 8, pp. 1024-1030, 2008.

[3] W. S. Smith, G. Sung, S. Starkman et al., "Safety and efficacy of mechanical embolectomy in acute ischemic stroke: results of the MERCI trial," Stroke, vol. 36, no. 7, pp. 1432-1438, 2005.

[4] A. D. Lopez, C. D. Mathers, M. Ezzati, D. T. Jamison, and C. J. Murray, "Global and regional burden of disease and risk factors, 2001: systematic analysis of population health data," The Lancet, vol. 367, no. 9524, pp. 1747-1757, 2006.

[5] C. D. Gandhi, L. D. Christiano, and C. J. Prestigiacomo, "Endovascular management of acute ischemic stroke," Neurosurgical Focus, vol. 26, no. 3, pp. 1-8, 2009.

[6] D. L. Brown, W. G. Barsan, L. D. Lisabeth, M. E. Gallery, and L. B. Morgenstern, "Survey of emergency physicians about recombinant tissue plasminogen activator for acute ischemic stroke," Annals of Emergency Medicine, vol. 46, no. 1, pp. 56-60, 2005.

[7] K. Z. Bambauer, S. C. Johnston, D. E. Bambauer, and J. A. Zivin, "Reasons why few patients with acute stroke receive tissue plasminogen activator," Archives of Neurology, vol. 63, no. 5, pp. 661-664, 2006. 
[8] K. Imai, T. Mori, H. Izumoto, and M. Watanabe, "Successful thrombectomy in acute terminal internal carotid occlusion using a basket type microsnare in conjunction with temporary proximal occlusion: a case report," The American Journal of Neuroradiology, vol. 26, no. 6, pp. 1395-1398, 2005.

[9] G. Wikholm, "Transarterial embolectomy in acute stroke," The American Journal of Neuroradiology, vol. 24, no. 5, pp. 892-894, 2003.

[10] T. E. Mayer, G. F. Hamann, and H. J. Brueckmann, “Treatment of basilar artery embolism with a mechanical extraction device: necessity of flow reversal," Stroke, vol. 33, no. 9, pp. 2232-2235, 2002.

[11] K. Hearon, K. Gall, T. Ware, D. J. Maitland, J. P. Bearinger, and T. S. Wilson, "Post-polymerization crosslinked polyurethane shape memory polymers," Journal of Applied Polymer Science, vol. 121, no. 1, pp. 144-153, 2011.

[12] D. Maitland, W. Small IV, P. Singhal et al., "Design and realization of biomedical devices based on shape memory polymers," in Proceedings of the Materials Research Society Symposium, A. Lendlein and P. Shastri, Eds., Cambridge University Press, New York, NY, USA, 2009.

[13] A. Lendlein and S. Kelch, "Shape-memory polymers," Angewandte Chemie -International Edition, vol. 41, no. 12, pp. 20342057, 2002.

[14] L. Petrini and F. Migliavacca, "Biomedical applications of shape memory alloys," Journal of Metallurgy, vol. 2011, Article ID 501483, 15 pages, 2011.

[15] T. K. Kim, J. K. Rhim, C. J. Lee, S. H. Oh, and B. S. Chung, "The limitations of thrombectomy with solitaire $\mathrm{AB}$ as first-line treatment in acute ischemic stroke: a single center experience," Journal of Cerebrovascular and Endovascular Neurosurgery, vol. 14, no. 3, pp. 203-209, 2012.

[16] W. Voit, T. Ware, R. R. Dasari et al., "High-strain shape-memory polymers," Advanced Functional Materials, vol. 20, no. 1, pp. 162-171, 2010.

[17] K. Otsuka and C. M. Wayman, Shape Memory Materials, Cambridge University Press, Cambridge, UK, 1999.

[18] P. Singhal, J. N. Rodriguez, W. Small et al., "Ultra low density and highly crosslinked biocompatible shape memory polyurethane foams," Journal of Polymer Science B, vol. 50, no. 10, pp. 724-737, 2012.

[19] W. Hwang, B. L. Volk, F. Akberali, P. Singhal, J. C. Criscione, and D. J. Maitland, "Estimation of aneurysm wall stresses created by treatment with a shape memory polymer foam device," Biomechanics and Modeling in Mechanobiology, vol. 11, no. 5, pp. 715-729, 2012.

[20] W. Small IV, T. S. Wilson, W. J. Benett, J. M. Loge, and D. J. Maitland, "Laser-activated shape memory polymer intravascular thrombectomy device," Optics Express, vol. 13, no. 20, pp. 8204-8213, 2005.

[21] W. Small, P. R. Buckley, T. S. Wilson et al., "Shape memory polymer stent with expandable foam: a new concept for endovascular embolization of fusiform aneurysms," IEEE Transactions on Biomedical Engineering, vol. 54, no. 6, pp. 11571160, 2007.

[22] K. Hearon, P. Singhal, J. Horn et al., "Porous shape-memory polymers," Polymer Reviews, vol. 53, no. 1, pp. 41-75, 2013.

[23] P. R. Buckley, G. H. McKinley, T. S. Wilson et al., "Inductively heated shape memory polymer for the magnetic actuation of medical devices," IEEE Transactions on Biomedical Engineering, vol. 53, no. 10, pp. 2075-2083, 2006.
[24] D. L. Safranski and K. Gall, "Effect of chemical structure and crosslinking density on the thermo-mechanical properties and toughness of (meth)acrylate shape memory polymer networks," Polymer, vol. 49, no. 20, pp. 4446-4455, 2008.

[25] L. E. Nielsen, "Cross-linking-effect on physical properties of polymers," Journal of Macromolecular Science C, vol. 3, no. 1, pp. 69-103, 1969.

[26] K. Hearon, L. D. Nash, B. L. Volk et al., "Electron beam crosslinked polyurethane shape memory polymers with tunable mechanical properties," Macromolecular Chemistry and Physics, vol. 214, no. 11, pp. 1258-1272, 2013.

[27] K. Hearon, S. E. Smith, C. A. Maher, T. S. Wilson, and D. J. Maitland, "The effect of free radical inhibitor on the sensitized radiation crosslinking and thermal processing stabilization of polyurethane shape memory polymers," Radiation Physics and Chemistry, vol. 83, pp. 111-121, 2012.

[28] A. M. Ortega, S. E. Kasprzak, C. M. Yakacki, J. Diani, A. R. Greenberg, and K. Gall, "Structure-property relationships in photopolymerizable polymer networks: effect of composition on the crosslinked structure and resulting thermomechanical properties of a (meth)acrylate-based system," Journal of Applied Polymer Science, vol. 110, no. 3, pp. 1559-1572, 2008.

[29] M. Trepanier and S. V. Franklin, "Column collapse of granular rods," Physical Review E, vol. 82, no. 1, Article ID 011308, 5 pages, 2010.

[30] J. Gralla, G. Schroth, L. Remonda et al., "A dedicated animal model for mechanical thrombectomy in acute stroke," The American Journal of Neuroradiology, vol. 27, no. 6, pp. 1357-1361, 2006.

[31] K. Stock, S. Wetzel, P. Lyrer, and E. Radü, "Quantification of blood flow in the middle cerebral artery with phase-contrast MR imaging," European Radiology, vol. 10, no. 11, pp. 1795-1800, 2000.

[32] D. A. Schiraldi and S. Iyer, "What does it take to make a stable POSS/polymer composite?" in Advances in Silicones and Silicone-Modified Materials, S. J. Clarson, S. D. Smith, and M. E. van Dyke, Eds., vol. 1051 of ACS Symposium Series, chapter 17, pp. 211-226, American Chemical Society, Washington, DC, USA, 2010.

[33] G. D. Gamble, J. Zorn, G. Sanders, S. MacMahon, and N. Sharpe, "Estimation of arterial stiffness, compliance, and distensibility from M-mode ultrasound measurements of the common carotid artery," Stroke, vol. 25, no. 1, pp. 11-16, 1994.

[34] W. A. Riley, R. W. Barnes, G. W. Evans, and G. L. Burke, "Ultrasonic measurement of the elastic modulus of the common carotid artery: the atherosclerosis risk in communities (ARIC) study," Stroke, vol. 23, no. 7, pp. 952-956, 1992. 

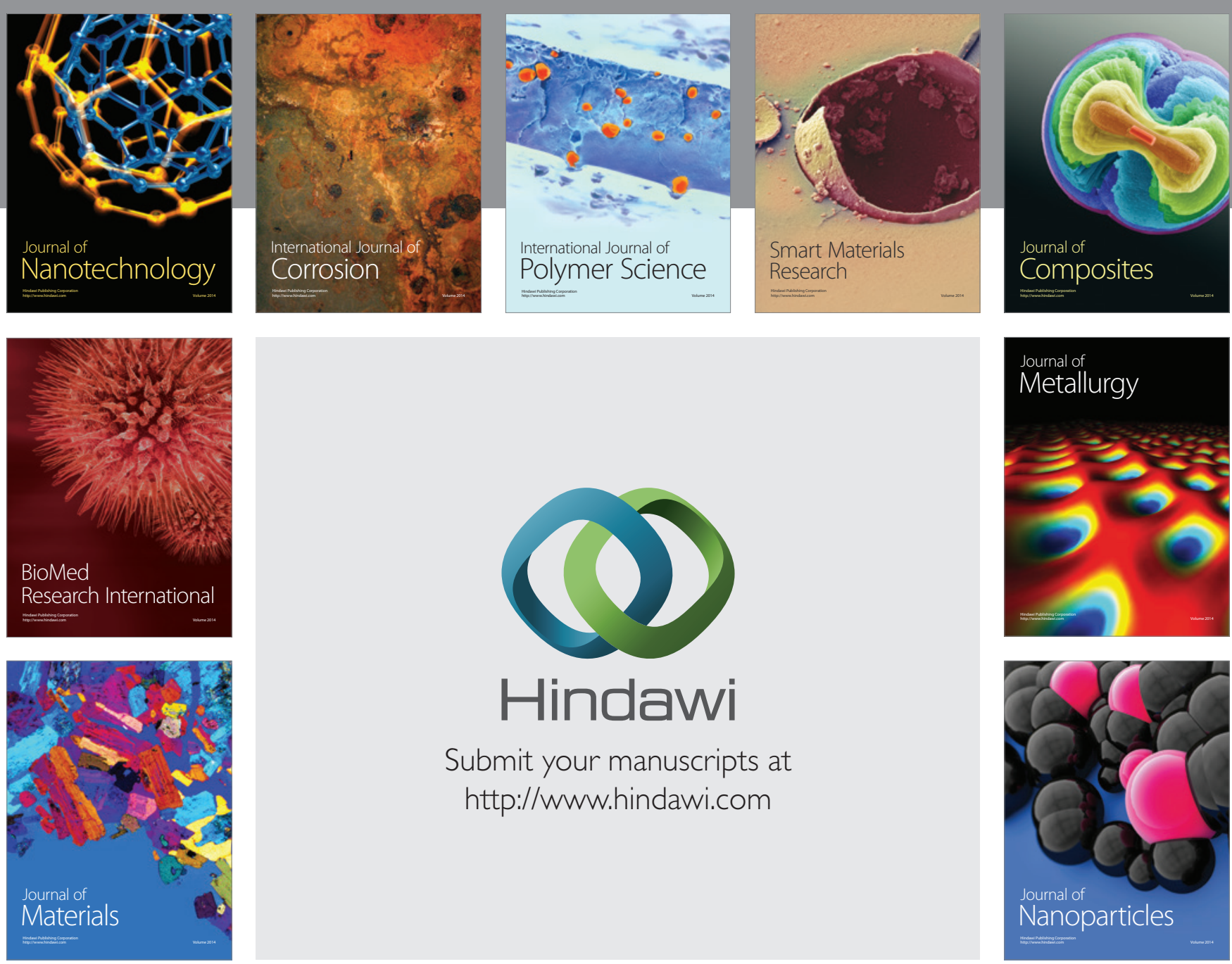

Submit your manuscripts at http://www.hindawi.com
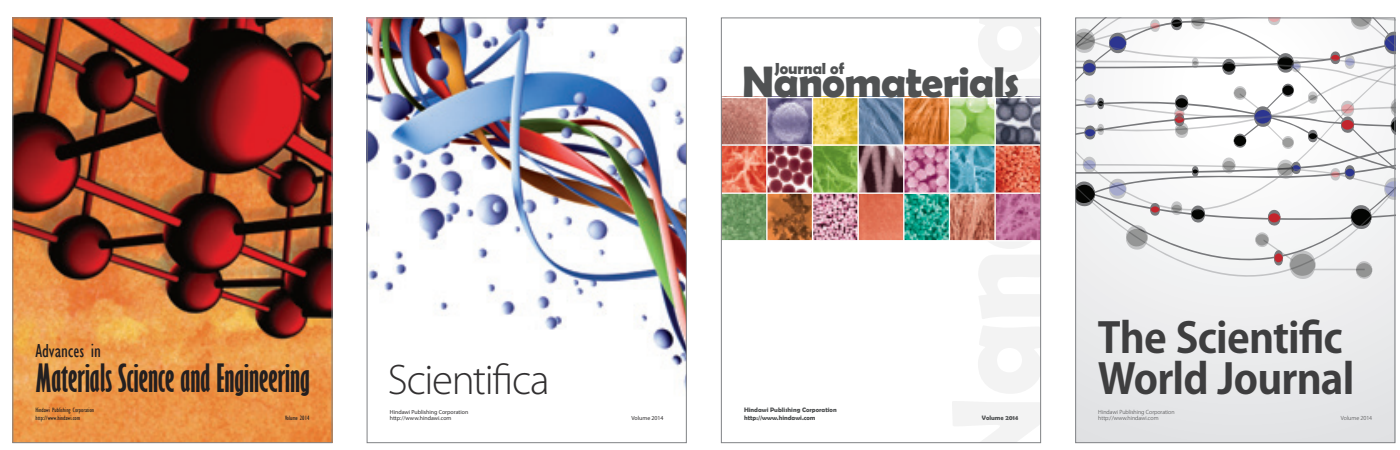

\section{The Scientific World Journal}
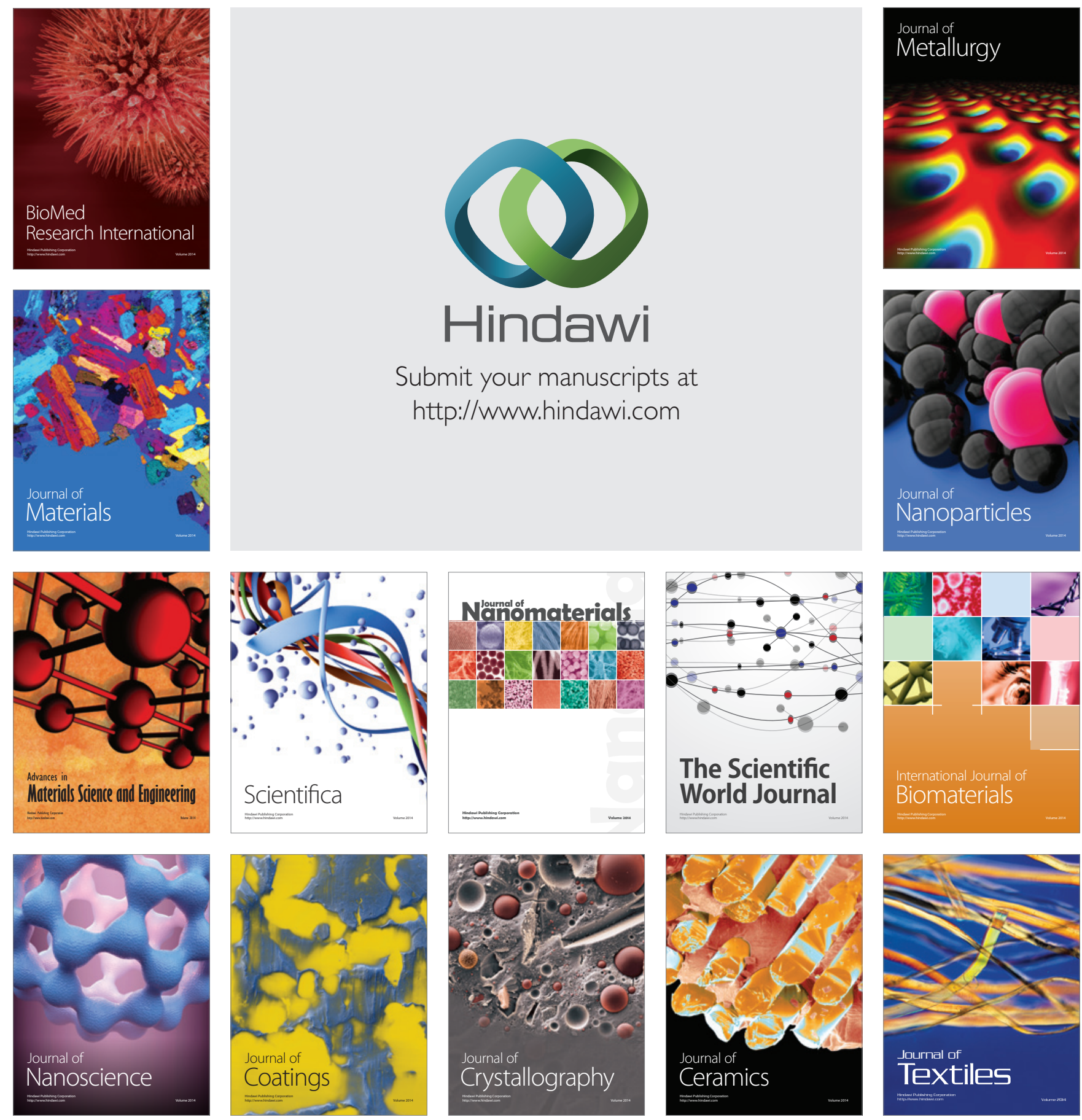